\title{
Correspondence
}

\section{Sexism: dearth of female role models}

Although "science remains institutionally sexist"(Nature 495, 21; 2013), gender inequality does not operate on its own. It is mediated by other inequalities, such as social class and race, which intersect.

Of the four researchers you use to illustrate the contribution of young, driven women to the scientific landscape (Nature $495,28-31 ; 2013$ ), at least two come from families in which both parents were scientists. This could well have habituated them in scientific practice from an early age. The reality is that most female scientists-intraining struggle to find female role models to smooth their transition into an academic career.

This effect is particularly isolating for women of African or Caribbean origin, who are among the most underrepresented groups in the sciences.

We call for rigorous qualitative research into the interaction of all these factors so that the occupational field can be cleared of cultural disadvantages for aspiring women and minority scientists.

Simon Williams, Christine Wood, Richard McGee Feinberg School of Medicine, Northwestern University, Chicago, Illinois, USA. simonwilliams@northwestern.edu

\section{Sexism: a revealing experiment}

Few of the depressing statistics on women in science pinpoint hard evidence for bias against individuals (see, for example, Nature 495, 22-24; 2013). So I conducted a small experiment of my own.

We know that successful grant applications are important drivers of promotion and tenure. In my first year as a researcher in 2005, I submitted 16 grant applications under my full name, which is not gender neutral. Just one received funding.

In my second year, I applied using only my initials and my last name: my success rate went up fivefold. This was only an $n=1$ experiment, but I didn't care to repeat it.

In my third year, the university adopted an electronic grantapplication system, which, unbeknown to me, automatically entered my full first name. In this blinded study, my success rate went down fivefold again, coincident with changing back to a female name on the application.

The following year, I asked the university to modify my entry to use only initials for my first names, thereby frustrating the automated system. My success rate went back up fivefold.

I am the same applicant. The replicates are low, but the outcome apparently differed only when it was obvious to the reviewers that I was female. Tina M. Iverson Vanderbilt University Medical Center, Nashville, Tennessee, USA. tina.iverson@vanderbilt.edu

\section{Sexism: science biographer responds}

In criticizing the stereotyping of female scientists, historian

and may have profound consequences for child-rearing.

\section{James Dwyer says:}

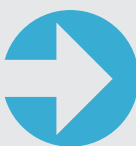

NATURE'S
READERS
COMMENT
ONLINE

A sample of responses from the debate on closing the gender gap in science (Nature 495, issue 7439; 2013).
Simply quantifying inequities does not provide indisputable evidence of discrimination. A complete quantitative analysis would require that pay differences be normalized by some reliable measure of job performance - of value to the employer. Likewise, the number and value of research grants awarded should be normalized by not just the number of applications, but ideally by some independent measure of their quality.

Julia Piaskowski says: The '30-something' women you describe are astounding in their abilities to keep their careers spinning, but they set a very high bar. This is unrealistic for the average female scientist
Patricia Fara creates a new stereotype - for biographies of female scientists (Nature 495, 43-44; 2013). She laments that they portray their subjects as weird, and protests against catchy titles, elements of cover design and the use of first names rather than surnames. As the author of one of the five books Fara criticizes, I would have welcomed a more substantive discussion. The challenges of writing scientific biography are more complex than she implies, whether the subject is female or male.

My book is, among other things, an exploration of the intertwined roles of truth and beauty in science, and of how a mathematician (Dorothy Wrinch) and a chemist (Linus Pauling) came to see them very differently. That difference is reflected in the title I Died for Beauty: Dorothy Wrinch and the Cultures of Science. I fail to see how, as Fara contends, this trivializes Wrinch's intellect. Marjorie Senechal Smith College, Northampton, Massachusetts, USA. senechal@smith.edu

be permanently ruined. But by getting off useless committees, removing junk-work from my schedule, delegating and becoming more efficient, I found myself producing just as much science half-time as I had been full-time. And there is a reason why sabbaticals are built into the academic career: we all need time to step back and re-evaluate, and spending time with our children can provide just this opportunity.

\section{Anna Sutton says:}

You know what's not helping? Quoting women saying "it's like not getting asked to dance". No wonder we're not asked to participate in technical and scientific activities if all we can do is focus on immature emotional reactions.
Vivian Zapf says:

When my children arrived, I switched to part-time working. I thought that my career would 